\title{
Clostridium perfringens em rações e águas fornecidos a frangos de corte em granjas avícolas do interior paulista - Brasil
}

\author{
Clostridium perfringens search in water and ration used in the raising of broiler in sheds \\ of São Paulo State-Brazil
}

\author{
Rubén Pablo Schocken-Iturrino ${ }^{*}$ Juliano Vittori $^{1}$ Mariana Casteleti Beraldo-Massoli $^{\mathrm{I}}$ \\ Tammy Priscilla Chioda Delphino ${ }^{\mathrm{I}}$ Priscila Regina Damasceno $^{\mathrm{I}}$
}

RESUMO

Através de métodos bacteriológicos convencionais, avaliou-se a contaminação por Clostridium perfringens na ração e água utilizadas na alimentação e dessedentação de frangos de corte em diferentes regiões avícolas do interior paulista. C. perfringens esteve presente em 42 e $30 \%$ das amostras de ração e águas analisadas, respectivamente. As médias das contagens foram $6,7 \times 10^{-2} \mathrm{UFC} \mathrm{mL}$ para as amostras de água e 3,69 × $10^{-2}$ UFC g para as de rações. As altas freqüencias e contagens de $\boldsymbol{C}$. perfringens verificadas nas rações e nas águas podem estar associadas à falta de higiene geral na manipulação e armazenamento dos mesmos. Sugere-se o monitoramento periódico da presença de $\boldsymbol{C}$. perfringens nestas fontes, com a finalidade de evitar tal patógeno, em vista que o mesmo pode causar um surto de enterite necrótica levando, assim a grandes prejuízos na produção avícola.

Palavras-chave: alimento, avicultura, contaminação, microbiologia, qualidade, Clostridium perfringens.

\section{ABSTRACT}

Through conventional bacteriological methods, the contamination by Clostridium perfringens was evaluated in the ration and water used in the feeding of poultry chickens from different region of the interior from São Paulo. $\boldsymbol{C}$. perfringens was present in 42 and $30 \%$ of the ration samples and waters analyzed respectively. The averages of the countings were $6.7 \times 10^{-2} \mathrm{CFU} \mathrm{mL}$ for the samples of water and $3.69 \times 10^{-2} \mathrm{CFU}$ $g$ for rations. The high frequencies and countings of $\boldsymbol{C}$. perfringens verified in the rations and in the waters may be associated to the lack of general hygiene in the manipulation and storage of the same ones. These suggests a periodic monitoration of the presence of $\boldsymbol{C}$. perfringens in these sources, with the purpose of avoiding such pathogen, in view that this organism can provoke an outbreak of necrotic enteritis, and cause great damages in the poultry production.

Key words: aviculture, contamination, food, microbiology, quality, Clostridium perfringens.

Dentre as diversas formas de veiculação de patógenos na cadeia de avicultura, destaca-se a contaminação das rações bem como a água de dessedentação. Essas fontes, quando contaminadas, podem veicular importantes patógenos ao plantel (JAENISCH, 2003), acarretando diminuição na eficiência alimentar e problemas de ordem sanitária, que culminam no desenvolvimento de doenças e consideráveis perdas econômicas e prejuízos a esse sistema de produção.

Diversos trabalhos na literatura têm relatado a presença de bactérias patogênicas na ração, matérias primas utilizadas na fabricação da mesma e na água de dessedentação (GAMA, 2005; VALIAS \& SILVA, 2001; SANTOS et al., 2000; ALBUQUERQUE et al., 1999; BERCHIERI et al., 1989), porém não são encontrados dados referentes a contaminação dessas fontes por Clostridium perfringens.

Comumente encontrado na microbiota intestinal dos humanos e de animais sadios, o aparecimento de patologias provocadas por esse microrganismo é dependente de circunstâncias que

IDepartamento de Patologia Veterinária, Faculdade de Ciências Agrárias e Veterinárias (FCAV), Universidade Estadual Paulista (UNESP), Campus de Jaboticabal, Jaboticabal, SP, Brasil. E-mail: pablo@fcav.unesp.br. *Autor para correspondência. 
favoreçam o crescimento e a produção em doses elevadas das toxinas clostridiais (GOMES ETAL, 2008). Esse microrganismo, especialmente os tipos A e C, é responsável pela enterite necrótica, doença bacteriana que em infecções subclínicas, provoca redução na absorção dos nutrientes e, conseqüentemente, menor ganho de peso e piora na conversão alimentar (SCHOCKEN-ITURRINO \& ISHI, 2000).

Sendo assim, visando-se avaliar a contaminação por $\boldsymbol{C}$. perfringens na ração e água utilizadas na alimentação e dessedentação de frangos de corte, foram realizadas colheitas de amostras de rações e águas durante o período de fevereiro a outubro de 2008 em três regiões avícolas, localizadas no interior do estado de São Paulo, sendo elas: Monte Alto (RMA), Descalvado (RD) e Sertãozinho (RS).

No total, foram coletadas 30 amostras de cada local, totalizando 180 amostras (90 de água e 90 de ração). Para a colheita das rações, foram utilizados um calador e sacos plásticos previamente esterilizados. Em cada saco de $50 \mathrm{~kg}$ contendo as rações que seriam utilizadas no arraçoamento do galpão, foram coletadas três amostras simples, em três diferentes profundidades. Estas, por sua vez, foram posteriormente misturadas e quarteadas, formando então uma amostra composta de 250 gramas, seguindo recomendações da SINDIRAÇÕES/ANFAL(1998).

A coleta da água foi realizada conforme a RDC n ${ }^{\circ} 275$ (Brasil 2005). Elas foram realizadas em três diferentes pontos da linha (início, meio e fim) de fornecimento de água em bebedouros do tipo pendular, sendo colocadas em garrafas de vidro de $250 \mathrm{~mL}$ estéreis. Após a colheita das amostras de ração e de água, as mesmas foram separadas em sacos plásticos e garrafas de vidro respectivamente, resfriadas e conservadas em caixas isotérmicas, sendo encaminhadas ao Laboratório para posteriores análises.

As amostras de ração e água foram quantificadas (25g de amostra de ração e $25 \mathrm{~mL}$ de água) e distribuídas em $225 \mathrm{~mL}$ de solução peptonada a $0,1 \%$, previamente esterilizadas, e submetidas à homogeneização manual, por três minutos. Foram realizadas diluições seriadas até $10^{-6}$, todas as diluições foram semeadas em duplicatas, pelo método "pour plate” em placas de petri contendo meio ágar sulfitopolimixina-sulfodiasina (SPS), previamente esterilizado. Essas placas foram incubadas em condições de anaerobiose utilizando jarras com um sistema Gás-Pak, à temperatura de $35-37^{\circ} \mathrm{C}$, por 24-48h (HOBBS, 1972; SPECK, 1976).

Para confirmar a pureza das colônias típicas, estas foram repicadas em placas contendo meio SPS e incubadas nas mesmas condições citadas anteriormente (SCHOCKEN-ITURRINO et al., 1988). Os esfregaços destas colônias foram corados pelo método de Gram para observação microscópica. Cinco colônias típicas de cada placa foram submetidas à série bioquímica a partir das colônias de bastonetes Grampositivos esporulados e catalase negativa, sendo estas repicadas em tubos de infusão de cérebro e coração (BHI- Difco), incubados em anaerobiose, a $37^{\circ} \mathrm{C}$, por 24 horas (SCHOCKEN-ITURRINO et al., 1988).

Os testes bioquímicos realizados foram: prova da gelatinase, motilidade, fermentação de lactose, maltose, sacarose, salicina, produção de indol, nitrato e $\mathrm{H}_{2} \mathrm{~S}$ (CARTER et al., 1995). Os dados das contagens microbianas foram transformados em Log 10 , sendo submetidos à análise estatística descritiva conforme SAMPAIO (1998).

Verificou-se que as amostras de ração provenientes de Monte Alto apresentaram maior contaminação, sendo que $45 \%$ das amostras da mesma região, $37 \%$ da $\mathrm{RS}$ e $42 \%$ da $\mathrm{RD}$ apresentaram-se positivas para a bactéria em questão (Tabela 1). Em relação às contagens, observou-se que nas amostras provenientes de RMA maior contagem média $(8,29 \mathrm{x}$ $10^{-3}$ UFC g), seguida pela RS (3,87 x $10^{-3} \mathrm{UFC}$ g) e, por último, a RD 2,51 x 10-3UFC g.

A constatação de altas contagens tem importância mesmo quando não causam problemas sanitários às aves, pois a presença de algumas bactérias no trato digestivo aumenta os níveis de contaminações de carcaças oriundas da abertura acidental do inglúvio ou dos intestinos por ocasião do abate (FIORENTIN, 2005) tornando-se, assim, também um problema de saúde publica.

Para as contagens de $\boldsymbol{C}$. perfringens nas amostras de água observou-se médias de 2,81 x $10^{2}$ $\mathrm{UFC} / \mathrm{mL}$ para as amostras RS, 9,35 x 10-2UFC mL para RMAe 7,95 x 10-2UFC mL para as amostras RD (Tabela 1). A qualidade físico-química e microbiológica da água é de grande importância, em vista que o fornecimento de água contaminada pode propagar doenças, especialmente, em aves jovens (NILIPOUR et al., 1996). O trato intestinal possui um sistema de defesa contra bactérias indesejáveis, que envolve o sistema imunológico e bactérias antagonistas. Porém, se houver um desequilíbrio desse sistema, as aves ficam suscetíveis a patógenos.

Tendo em vista o prolongado tempo de sobrevivência de alguns microorganismos patogênicos na água e o grande número de aves que têm acesso à mesma fonte de água, a transmissão hídrica assume um fundamental papel na epidemiologia de várias enfermidades aviárias (GAMA, 2005). Da mesma forma, acredita-se que a bactéria em questão, quando em altos números, como verificado neste trabalho, possa agir de inócuo no intestino das aves para dar inicio a um 
Tabela 1 - Contagens (Médias e desvios-padrão) e porcentagem de amostras positivas para $\boldsymbol{C}$. perfringens, em amostras de ração e água, provenientes de diferentes regiões avícolas, colhidas no período de agosto de fevereiro a outubro de 2008.

\begin{tabular}{|c|c|c|}
\hline Regiões Estudadas & $\begin{array}{l}\text { Média e desvio } \\
\text { padrão }\end{array}$ & $\begin{array}{c}\text { Amostras positivas } \\
\text { (\%) }\end{array}$ \\
\hline & RAÇÃO & RAÇÃO \\
\hline & $\mathrm{UFC}^{-1}$ & \\
\hline Sertãozinho (SP) & $3,87 \times 10^{3} \pm 13,01$ & 37 \\
\hline Descalvado (SP) & $2,51 \times 10^{3} \pm 17,57$ & $42 *$ \\
\hline \multirow[t]{3}{*}{ Monte Alto (SP) } & $8,29 \times 10^{3} \pm 31,47$ & 45 \\
\hline & ÁGUA & ÁGUA \\
\hline & $\mathrm{UFC} / \mathrm{mL}$ & \\
\hline Sertãozinho (SP) & $2,81 \times 10^{2} \pm 33,20$ & 39 \\
\hline Descalvado (SP) & $7,95 \times 10^{2} \pm 11,64$ & $30 *$ \\
\hline Monte Alto (SP) & $9,35 \times 10^{2} \pm 15,41$ & 24 \\
\hline
\end{tabular}

* = Média do total de amostras analisadas.

quadro de enterite necrótica, dependendo dos fatores de predisposição a que essas aves estejam expostas, tais como uma infecção concomitantemente por coccídea (LILLEHOJ et al., 2007).

As altas freqüências e contagens de $\boldsymbol{C}$. perfringens verificadas nas rações e nas águas podem estar associadas à falta de higiene geral na manipulação e armazenamento dos mesmos. Sugere-se o monitoramento periódico da presença de $\boldsymbol{C}$. perfringens nestas fontes, com a finalidade de evitar tal patógeno, em vista que o mesmo pode causar grandes prejuízos na produção avícola.

\section{REFERÊNCIAS}

ALBUQUERQUE, R.; et al. Estudo da Ocorrência de Salmonelas em Ingredientes, Rações e Suabes de Pó Colhidos em uma Fábrica Industrial de Ração. Brazilian Journal of Veterinary Research and Animal Science, São Paulo, v. 36, n. 6, p. 324-326, 1999. Disponível em: <http://www.scielo.br/scielo.php?pid=S141395961999000600008\&script=sciabstract\&tlng=pt $>$.doi: $10.1590 /$ S1413-95961999000600008. Acesso em 03/04/2007.

BERCHIERI Jr, A.; et al. Farinha de carne como fonte de Salmonella em granja avícola. Pesquisa Veterinária brasiliera, Rio de Janeiro, v.9, n.1-2, p.9-12, 1989.

BRASIL 2005; Ministério da Saúde. Agência Nacional de Vigilância Sanitária. Resolução $n^{\circ} 275$, de 22 de setembro de 2005. Regulamento Técnico de Características Microbiológicas para Água Mineral Natural e Água Natural. Diário Oficial da União. Brasília, 23 de setembro de 2005.

CARTER, G. R.; et al. Essencialts of veterinary microbiology. 5. ed. London: Willians \& Wilkins, 1995. p.394.

FIORENTIN, L. Aspectos bacteriológicos da reutilização da cama de aviários de frangos de corte: versão eletrônica. EMBRAPA Suínos e Aves, p. 05, 2005.
GAMA, N. M. S. Q. Qualidade química e bacteriológica da água utilizada em granjas produtoras de ovos. 2005. 87f. Tese (Doutorado em Medicina Veterinária - Patologia Animal) - Faculdade de Ciências Agrárias e Veterinárias, Universidade Estadual Paulista, Jaboticabal.

GOMES, A. M. et al.Genotipicação de Clostridium perfringens isolados de frangos de corte através da PCR múltipla. Ciência Rural, Santa Maria, p. 1943 - 1947, v.38, n.7 Oct. 2008. Disponível em: <http://www.scielo.br/scielo.php?pid=S01038478200800070002\& script=sciabstract\&tlng=e>. doi: 10.1590/S0103-84782008000700022. Acesso em 02 de fevereiro de 2009.

HOBBS, B. C. Clostridium perfringens and Bacillus cereus infections. In: RIEMANN, H. Food borne infections and intoxications. New York: Academic Press, 1972. p. 131-173.

LILLEHOJ, H.S.; et al. Innate immune response to Clostridium perfringens and Eimeria maxima in necrotic enteritis model. Proceedings of America Avian Veterinary Pathologists, July 14-18, Washington, D.C.

JAENISCH, F. R. F. Sistemas de Produção de Frangos de Corte: Cuidados com a ração e a água. Embrapa Suinos e Aves. 2003. Acessado em 21 de fev. de 2009. Online. Disponível em: <http://sistemasdeproducao.cnptia.embrapa.br/FontesHTML/ Ave/ ProducaodeFrangodeCorte/Cuidados-racao.html>.

NILIPOUR A.H.; et al. Effect of varying brooding temperature and water chlorination on performance parameters. Savoy Poultry Science Abstracts 1996; 75(suppl. 1): 134.

SAMPAIO, I.B.M. Estatística aplicada à experimentação animal. Belo Horizonte: Fundação de Ensino e Pesquisa em Medicina Veterinária e Zootecnia, 1998. Estatística descritiva básica, p.14-19.

SANTOS, E.J.; et al. Qualidade microbiológica de farinhas de carne e ossos produzidas no estado de Minas Gerais para produção de ração animal. Ciência agrotécnica (Universidade Federal de Lavras), v.24, n.2, p.425-433, 2000.

SCHOCKEN-ITURRINO, R. P.; et al. Isolation and characterization of pathogenic Clostridium in meats products. Ars Veterinária, Jaboticabal, v. 4, n. 1, p. 91-98, 1988.

SCHOCKEN-ITURRINO, R. P.; ISHI, M. Clostridioses em aves. In: BERCHIERI, A. JR.;MACARI, M. Doenças das aves. Campinas: Facta, p.800, 2000.

SECRETARIA EXECUTIVA DO SINDIRAÇÕES/ANFAL. Compendium Brasileiro de Alimentação. Cap VII. São Paulo: Análise Fiscal e Pericial, 1998. p.19.

SPECK, M. L. Compendium of methods for the microbiological examination of foods. Washington: APHA, 1976. p. 701.

VALIAS, A. P. G. S.; SILVA, E. N. Estudo Comparativo de Sistemas de Bebedouros na Qualidade Microbiológica da Água Consumida por Frangos de Corte. Revista Brasileira de Ciência Avícola, Campinas, v. 3, n. 1, p. 83-89, 2001. Disponível em: <http:// w w w. s c i e l o.b r / s c i e lo.ph p ? p i d = S 1516 35X2001000100009\&script=sci_arttext\&tlng=es $>$. doi: 10.1590/ S1516-635X2001000100009. 